fact it seems that great care has been taken to give both sides of controversial problems. It is, for example, pleasant to find clearly stated the alternative hypotheses required if that of continental drift be not accepted, or again, to see a discussion of Dr. Tucker's views on the breeding of eels after the classical account is given.

In general, all the interpolations and additions in this revision are judicious and valuable, and few topics which have arisen since Norman's day, or have increased in importance since he wrote, are not to be found in this new edition. It is a pity that space could not be found for a discussion of the effects of the land-locked sea lampreys of the Great Lakes on the commercial fisheries there, perhaps the most striking example to be found of the direct competition of men and fishes for the same food source (particularly as the statement about the value of these fisheries on p. 335 is scarcely true to-day); but in less than 400 pages there must be some omissions.

Very few errors or ambiguities were detected by me but three may be mentioned. It is difficult to understand tho distinctions drawn in this edition between true and virtual parasitism, both terms being applied to the special case of the dwarf males of certain angler fishes (pp. $211 ; 244$ ) which live attached to the females.

One error in the first edition which has not been remedied is that the female ray of Fig. 101 (Fig. 107 of the first edition) is in fact an immature male, and this is unfortunate, since the figure purports to show the difference between the male and the female. Finally, it is something of a surprise to find that Dr. Greenwood has placed the lancelet, Branchiostoma, among the Hemichordates (p. 258).

These are minor defects, and Dr. Greenwood is to be congratulated on a very successful revision of one of the best popular books on fish. It would be difficult to find so much information so well presented in any other book of comparable size and price, and this new edition well deserves the success of its predecessor. Q. Bone

\section{CLASSIFICATION OF NEMATODES}

\section{Soil and Freshwater Nematodes}

By Dr. T. Goodey. Second edition, revised and rewritten by Dr. J. B. Goodey. Pp. xvi + 544. (London: Methuen and Co., Ltd.; New York: John Wiley and Sons, Inc., 1963.) 100s. net.

TEMATOLOGISTS have looked forward to a new edition of this outstanding work on the classification of the soil- and fresh-water inhabiting and plant-parasitic nematode genera for quite some time already. The first edition has been out of print for many years now. Moreover, large sections of the book were becoming more and more out of date. To incorporate the large amount of new information which has become available since the first edition was published this new edition has been entirely rewritten, and expanded from about 400 to more than 600 pages. The number of illustrations has increased from 190 to 298 and a larger format has been chosen. Several illustrations have benefited from the better-quality paper than that used for the first edition. However, the reviser has justifiably maintained the original plan of the book.

Contrary to other more or less similar works (for example, Meyl's Freilebende Nematoden in Die Tierwelt Mitteleuropas 1, 5a, 1960) which are compilations of extremely abbreviated descriptions of species, the new edition of Soil and Freshwater Nematodes, like the first, concentrates on the definition of genera and their classification in higher categories. The definition of each genus is followed by an illustrated description of the type species or of another characteristic species if this serves the purpose better: to make the genus definition more than an abstraction and therefore much easier to use.
It is this judicious combination of definitions of higher systematic categories with full descriptions and illustrations of a limited number of species which makes the book so usable also to non-taxonomists. The species belonging to a genus are listed alphabetically with author, date and synonyms after the description of the type or representative species and the section on each genus closes with a paragraph on the bionomics of its members. An improvement compared to the first edition is the insertion of tabular keys at the beginning of each systematic category. They are not the usual dichotomous keys but tables which list in columns the members of the category with, under appropriate headings (cuticle, stoma, œsophagus, etc.), their taxonomically important features. The tables are intended to enable the reader to determine the order, family and genus to which specimens actually belong, but they also make a comparison of the members of the category possible, thereby providing a quick insight in the concepts the classification has been based on.

In adapting the classification to the present state of knowledge the reviser has not only made a choice from the various concepts found in the literature but has also expressed his own, hitherto unpublished, views. He has reduced the status of the nematodes from that of a phylum to that of a class with the name Nematodea and abandoned the division into Phasmidia (Secernentes) and Aphasmidia (Adenophori). On the other hand, several lower categories have been raised in rank and a division of the genera under consideration in ten orders instead of the four of the first edition has been adopted, resulting in a higher degree of uniformity within most of them.

The orders Tylenchida and Rhabditida were maintained virtually unchanged apart from placing Teratocephalus and Euteratocephalus (formerly in Rhabditida) in a new order Teratocephalida. Within these orders considerable changes in classification were made. The Chromadorida and the Enoplida of the first edition are now divided into four and two orders respectively : Araeolaimida, Desmoscolecida, Monhysterida, Chromadorida, Enoplida and Dorylaimida.

One could scarcely expect systematists not to disagree with the classification of the original author and of the reviser on several points. For example, I question the inconsistency in the evaluation of the structure of the osophagus in the Tylenchoidea, allowing it to prevail over all other characters in one case (Neotylenchidae) and giv. ing it only secondary importance in others. I must admit, however, that it will not be easy to find entirely satisfactory alternatives in this and other cases unless new material and a better knowledge of nematode anatomy, for example of the topography of the csophageal glands in Tylenchoidea, give us a better insight in systematic relationships.

Neither queries nor differences of opinion, however, suggest that the new edition of Soil and Freshwater Nematodes is not an excellent work and of great importance to all those who study nematodes as taxonomists, plant pathologists or while engaged in faunistic studies.

\section{J. W. SEINHORST}

\section{INDIAN WATER PLANTS}

\section{Aquatic Angiosperms}

A Systematic Account of Common Indian Aquatic Angiosperms. By K. Subramanyam. (Botanical Monograph No. 3). Pp. viii +190 (illustrations). (New Delhi: Council of Scientific and Industrial Research, 1962.) Rs. $20.00 ; 40 s$; 6.00 dollars.

HIS book is the third in a series of botanical monographs published by the Council of Scientific and Industrial Research, New Delhi, with the aim of collecting together the scattered results of researches published in 